\title{
Multiculturalism and Value Education in History Learning (Case Study at SMAN 1 Kartasura)
}

\section{Teodorikus Hanpalam}

Universitas Sebelas maret

teodorikushanpalam@gmail.com

\author{
Article History \\ accepted 1/09/2020
}

approved 4/10/2020

published 1/12/2020

\begin{abstract}
This research was conducted at SMA Negeri 1 Kartasura. This study aims to: (1). To find out the role of multiculturalism in value education. (2). To find out historical learning based on multiculturalism values. The research method used in this research is descriptive analysis with a single case study research strategy. Sources of data in this study are informants, places/locations, and events, as well as documents and archives. The sampling technique used in this research is purposive sampling and time sampling. The technique of data validity is done by triangulation of data/sources and triangulation of methods. The data analysis technique used in this research is an interactive analysis. Benefits of Research: (1). As an illustration regarding the role of multiculturalism in value education. (2). To understand more deeply about historical learning based on multiculturalism values.
\end{abstract}

Keywords: Multiculturalism, value education, history learning

\begin{abstract}
Abstrak
Penelitian ini dilakukan di SMA Negeri 1 Kartasura. Penelitian ini bertujuan untuk: (1). Untuk mengetahui peran multikulturalisme dalam pendidikan nilai. (2). Untuk mengetahui pembelajaran sejarah berbasis nilai multikulturalisme. Metode Penelitian yang dilakukan dalam penelitian ini adalah deskriptif analisis dengan strategi penelitian studi kasus tunggal. Sumber data dalam penelitian ini adalah informan, tempat/lokasi dan peristiwa, serta dokumen dan arsip. Teknik cuplikan (sampling) yang digunakan dalam penelitian ini adalah Purposive Sampling dan Time Sampling. Teknik validitas data dilakukan dengan trianggulasi data/sumber dan trianggulasi metode. Teknik analisis data yang dilakukan dalam penelitian ini adalah analisis interaktif. Manfaat Penlitian: (1). Sebagai gambaran terkait bagaimana peran multikulturalisme dalam pendidikan nilai. (2). Untuk memahami lebih dalam tentang pembelajaran sejarah berbasis nilai multikulturalisme.
\end{abstract}

Kata Kunci: Multikulturalisme, pendidikan nilai, pembelajaran sejarah

Social, Humanities, and Education Studies (SHEs): Conference Series p-ISSN 2620-9284 https://jurnal.uns.ac.id/shes e-ISSN 2620-9292 


\section{PENDAHULUAN}

Kemajemukan merupakan salah satu ciri masyarakat Indonesia. Banyak orang yang belum juga menyadari bahwa kemajemukan tersebut juga menyimpan potensi konflik yang dapat mengancam kehidupan berbangsa dan bernegara. Oleh sebab itu adalah sangat penting untuk menanamkan nilai-nilai multikultural sejak awal pada anggota masyarakat Indonesia, agar mekanisme dan nilai-nilai substantif (dalam demokrasi) dipahami secara benar. Sebab nilai-nilai multikultural dan nlai-nilai demokrasi memuat nilai humanisme seperti keadilan, empati, kebersamaan, dan mampu menerima perbedaan.

Salah satu institusi sosial penting dan strategis guna menanamkan konstruks yang lebih bersimpati dan berempati terhadap kemajemukan adalah melalui institusi pendidikan.

Tekanan multikulturalisme bisa kita transfer ke dalam pembelajaran di sekolah. Maka gagasan pembelajaran bercorak multikultural, bisa dipahami sebagai suatu proses penyadaran terhadap adanya keanekaragaman serta kesediaan memberlakukan setiap etnis, budaya dan agama secara egaliter.

Merupakan kenyataan yang tak bisa ditolak bahwa negara-bangsa Indonesia terdiri dari berbagai kelompok etnis, budaya, agama dan lain-lain sehingga negarabangsa Indonesia disebut sebagai bangsa multikultural. Tetapi tataran praksis, realitas multikultural tersebut berhadapan dengan kebutuhan mendesak untuk merekonstruksi kembali "kebudayaan nasional Indonesia" yang dapat menjadi "integrating force" yang mengikat seluruh keragaman etnis, agama dan budaya tersebut. Ben Senang Galus dalam Menalar Negara (2014).

Undang-undang Nomor 20 Tahun 2003 tentang Sistem Pendidikan Nasional (Pasal 3) mengamanatkan bahwa pendidikan nasional berfungsi mengembangkan kemampuan dan membentuk watak serta peradaban bangsa yang bermartabat dalam rangka mencerdaskan kehidupan bangsa. Selanjutnya ditegaskan bahwa pendidikan nasional bertujuan mengembangkan potensi peserta didik menjadi manusia yang beriman dan bertaqwa kepada Tuhan Yang Maha Esa, berakhlak mulia, sehat, berilmu, cakap, kreatif, mandiri, dan menjadi warga negara yang demokratis serta bertanggungjawab.

Tujuan pendidikan nasional tersebut menyiratkan bahwa melalui pendidikan hendak diwujudkan peserta didik yang memiliki berbagai kecerdasan, baik kecerdasan spiritual, emosional, sosial, intelektual maupun kecerdasan kinestetika serta rasa tanggung jawab sebagai warga negara yang multikultural.

Pendidikan nasional memiliki misi mulia (mission sacre) terhadap anak didik, yaitu membangun pribadi yang memiliki ilmu pengetahuan, meningkatkan kemampuan teknis, mengembangkan kepribadian yang kokoh dan membentuk karakter yang kuat yang mengedepankan nilai-nilau luhur bangsa Indonesia yang telah ditegaskan dalam sila-sila Pancasila.

Terbentuknya karakter peserta didik yang kuat dan kokoh diyakini merupakan hal yang penting dan mutlak dimiliki setiap peserta didik untuk menghadapi tantangan hidup di masa mendatang. Tilaar, (2004). Multikulturalisme adalah "konsep pembudayaan, dan oleh karena proses pendidikan adalah proses pembudayaan, maka masyarakat multikultural dapat diciptakan melalui proses pendidikan".

Pendidikan dan pembudayaan merupakan suatu proses pembentukan karakter bangsa dan warga negara. Pendidikan multikultural adalah pendidikan yang berbasis multikulturalisme. Pendidikan yang mengedapankan keberagaman dan menjunjung tinggi peradaban dan moral anak bangsa. 


\section{METODE}

Metode Penelitian yang dilakukan dalam penelitian ini adalah deskriptif analisis dengan strategi penelitian studi kasus tunggal. Sumber data dalam penelitian ini adalah informan, tempat/lokasi dan peristiwa, serta dokumen dan arsip. Teknik cuplikan (sampling) yang digunakan dalam penelitian ini adalah Purposive Sampling dan Time Sampling. Teknik validitas data dilakukan dengan trianggulasi data/sumber dan trianggulasi metode. Teknik analisis data yang dilakukan dalam penelitian ini adalah analisis interaktif.

\section{HASIL DAN PEMBAHASAN \\ Peran Multikulturalisme Dalam Pendidikan Nilai}

Multikulturalisme di Indonesia bersumber pada Undang-Undang Dasar 1945 yang menyatakan bahwa bangsa dan masyarakat Indonesia terdiri dari beragam kelompok etnis yang memiliki komitmen untuk membangun Indonesia sebagai negarabangsa. Komitmen dan pengakuan tersebut dinyatakan dalam simbol garuda Pancasila. Simbol ini menyatakan kehidupan kebangsaan itu memilukan persyarat, yaitu adanya toleransi sebagai bentuk penghargaan atas keberadaan kebudayaan masyarakat Indonesia yang beragam (Bhinneka Tunggal lka).

Keberagaman di Indonesia itu sudah lama ada. Tetapi multikultur adalah soal bagaimana memahami kebudayaan itu sendiri. Saat ini, orang masih menganut totemisme dan perbedaan dinilai bukan hal yang menyenangkan. Setiap kelompok lalu mulai membuat teritorial. Jika bahasa Indonesia saja bisa lintas batas, seharusnya konstruksi budaya juga demikian. Identitas semestinya sebuah konstruksi yang dipegang sebagai hal pribadi. "Orang tidak perlu menjadi asli untuk bisa mencintai Indonesia". Tetapi solidaritas dan toleransi dan keterbukaan sebenarnya sudah ditampilkan tanpa gagasan multikultur.

Pendekatan multikultur relatif baru dianggap sesuai bagi masyarakat Indonesia yang heterogen. Hal itu makin dirasakan terutama pada masa otonomi dan desentralisasi. Tanpa pendekatan multikultur, disintegrasi bangsa yang semula dianggap ancaman mungkin akan menjadi kenyataan. Dikatakan, pendekatan multikultur sangat cocok dan sejalan dengan pengembangan demokrasi yang mulai dijalankan.

Pada dasarnya, multikulturalisme yang terbentuk di Indonesia merupakan akibat dari kondisi sosio-kultural maupun geografis yang begitu beragam dan luas. Menurut kondisi geografis, Indonesia memiliki banyak pulau dimana setiap pulau tersebut dihuni oleh sekelompok manusia yang membentuk suatu masyarakat. Dari masyarakat tersebut terbentuklah sebuah kebudayaan mengenai masyarakat itu sendiri. Tentu saja hal ini berimbas pada keberadaan kebudayaan yang sangat banyak dan beraneka ragam.

Multikultural dapat terjadi di Indonesia karena:

1. Letak geografis indonesia

2. Perkawinan campur

3. Iklim

Multikultural di Indonesia bersifat normatif. Multikulural normatif adalah petunjuk tentang berbagai kepentingan yang membimbing pada pengakuan yang lebih tinggi mengenai kebangsaan dan identitas kelompok yang berbeda di dalam masyarakat. Multikultural normatif di Indonesia pertama kali diamanatkan dalam UUD 1945. Ketentuan di dalam UU menyatakan bahwa rakyat dan bangsa Indonesia mencakupi berbagai kelompok etnis. Mereka telah berbagi komitmen dalam membangun bangsa Indonesia.

Dalam sistem kurikulum 2013, semua guru adalah pengajar pendidikan nilai tanpa kecuali. Pembelajaran berbasis nilai-nilai adalah pembelajaran yang digunakan guru untuk memfasilitasi peserta didik dalam menguasai seperangkat rumusan 
kompetensi, dengan mengedepankan dan mengacu pada nilai-nilai (Gufron dkk, 2017: 310). Pembelajaran berbasis nilai dapat disajikan melalui analisis nilai-nilai. Peserta didik dapat menemukan nilai dibalik peristiwa sejarah tertentu kemudian menganalisis nilai-nilai tersebut. Pembelajaran berbasis nilai lebih mengedepankan masalah nilai yang dapat digunakan sebagai bahan pertimbangan peserta didik dalam bertindak. Diharapkan pembelajaran berbasis nilai dapat memperkuat karakter peserta didik sesuai dengan harapan kurikulum 2013. Pembelajaran berbasis nilai membutuhkan keterpaduan antara aspek kognitif, afektif, dan psikomotorik.

Tujuan utama pendidikan nilai adalah terjadinya perubahan sikap, sifat, dan perilaku peserta didik ke arah yang positif melalui transfer dan transmisi sistem nilai. Untuk mengetahui perubahan tersebut, maka harus ada ukuran minimal untuk menilai apakah seorang peserta didik telah mengalami perkembangan kualitas karakter atau moral. Seorang anak akan dinilai telah mempunyai karakter yang baik jika ia mampu mengaplikasikan nilai kebaikan dalam bentuk tingkah laku di tengah-tengah masyarakat yang multikultural.

\section{Pembelajaran Sejarah Berbasis Nilai Multikulturalisme}

Pembelajaran adalah proses kerjasama antara guru dengan siswa dalam memanfaatkan segala potensi dan sumber yang ada baik itu potensi yang bersumber dari dalam siswa itu sendiri seperti bakat, minat, dan kemampuan dasar yang dimiliki termasuk gaya belajar maupun potensi yang ada di luar diri siswa seperti lingkungan, sarana, dan sumber belajar sebagai upaya untuk mencapai tujuan belajar tertentu. Sebagai suatu proses kerja sama, pembelajaran tidak hanya menitikberatkan pada kegiatan guru atau kegiatan siswa saja, akan tetapi guru dan siswa secara bersamasama berusaha mencapai tujuan pembelajaran yang telah ditentukan (Sanjaya, 2008:26).

Sejarah merupakan cabang ilmu pengetahuan yang menelaah tentang asalusul dan perkembangan serta peranan masyarakat di masa lampau berdasarkan metode dan metodologi tertentu. Sejarah (studi tentang manusia beserta perkembangannya yang melewati abad-abad keberhasilan) dapat dikatakan berasal dari manusia itu sendiri. Dengan demikian, dapat dikatakan bahwa sejarah adalah sebuah ilmu yang berusaha menemukan, mengungkapkan, serta memahami nilai dan makna budaya yang terkandung dalam peristiwa-peristiwa masa lampau (Abdurahman, 1999: 3).

Dari pengertian pembelajaran dan pengertian sejarah diatas dapat disimpulkan bahwa pembelajaran sejarah adalah suatu aktivitas belajar mengajar, dimana seorang guru menerangkan pada siswanya tentang gambaran kehidupan masyarakat masa lampau yang menyangkut peristiwa-peristiwa penting dan memiliki arti khusus.

Menurut Aman (2011: 5), mata pelajaran sejarah secara rinci memiliki 5 tujuan agar peserta didik memiliki kemampuan sebagai berikut: (1) membangun kesadaran peserta didik tentang pentingnya waktu dan tempat yang merupakan sebuah proses dari masa lampau, masa kini, dan masa depan; (2) melatih daya kritis peserta didik untuk memahami fakta sejarah secara benar dengan didasarkan pada pendekatan ilmiah dan metodologi keilmuan; (3) menumbuhkan apresiasi dan penghargaan peserta didik terhadap peninggalan sejarah sebagai bukti peradaban bangsa Indonesia di masa lampau; (4) menumbuhkan pemahaman peserta didik terhadap proses terbentuknya bangsa Indonesia melalui sejarah yang panjang dari masih berproses hingga masa kini dan masa yang akan datang; (5) menumbuhkan kesadaran peserta didik sebagai bagian dari bangsa Indonesia yang memiliki rasa bangga dan cinta tanah air yang dapat diimplementasikan dalam berbagai bidang kehidupan baik nasional maupun internasional.

Ruang lingkup pembelajaran sejarah diawali dari masa lampau, dan membuat masa kini sebagai tempat berlabuh dan persinggahan untuk ke masa depan. Berbagai peristiwa seperti perang, revolusi, berdirinya dan jatuhnya kerajaan, keberuntungan dan 
kemalangan para pendiri kekaisaran dan juga rakyatnya merupakan kajian sejarah. Sejarah adalah ilmu yang komprehensif. Studi sejarah yang pada awalnya terbatas pada hikayat, berabad-abad kemudian menjadi sejarah umum peradaban manusia, yang melukiskan keberhasilan manusia dalam setiap aspek kehidupan politik, ekonomi, sosial, budaya, teknologi, religi, seni, dan lain-lain, dan pada berbagai tingkatan lokal, regional, nasional, dan internasional (Kochhar, 2008:16-17).

Pembelajaran sejarah yang berbasis multikultural butuh peran berbagai pihak terutama guru dan pemangku kepentingan yang membuat dan menyusun kurikulum. Sehingga pembelajaran sejarah memilki makna dan menjadi sarana dalam mewariskan nilai-nilai luhur bangsa Indonesia.

Dalam mempelajari sejarah tidak akan berarti apabila tidak disertai dengan pemahaman akan nilai yang terkandung dalam bentuk, fungsi, dan maknanya. Tidak bisa dibantah bahwa manusia pada umumnya gemar menggunakan pengalamanpengalaman itu sebagai pedoman atau contoh untuk memperbaiki kehidupannya Patminingsing (1994:2). Jadi pembelajaran sejarah adalah belajar tentang nilai dan bukan menghafal peristiwa atau kejadian, karena nilai yang terkandung dalam setiap peristiwa memiliki kegunaan sebagai pelajaran untuk masa kini dan masa yang akan datang.

Hasan Hamid,( 2007:7) berpendapat bahwa terdapat beberapa pemaknaan terhadap pendidikan sejarah. Petama, secara tradisional pendidikan sejarah dimakanai dengan sebagai salah satu upaya utuk mentransfer kemegahan dan kerusakan bangsa dimasa lampau kepada generasi muda dan yang akan datang. Dengan posisi yang demikian maka pendidikan sejarah adalah sarana bagi pewarisan nilai-nilai keunggulan bangsa. Melalui posisi ini pendidikan sejarah bertujuan untuk membangun kebanggaan bangsa dan pelestarian keunggulan tersebut. Kedua, pendidikan sejarah berkenaan dengan upaya memeperkenalkan peserta didik terhadap disiplin ilmu sejarah. Oleh karena itu, kualitas seperti berpikir kronologis, pemahaman sejarah, kemampuan analisis isu dan pengambilan keputusan (historical issuesanalysis and decision making) menjadi tujuan penting dalam pendidikan sejarah.

\section{SIMPULAN}

Indonesia merupakan negara kepulauan yang sangat multikultural memiliki beragam suku, budaya, bahasa dan agama. Realita ini merupakan suatu keniscayaan dan kekayaan yang dimiliki bangsa. Atas dasar keberagaman itu, kehadiran Pancasila sebagai titik temu merupakan suatu solusi dan penyatu segala perbedaan, karena Pancasila lahir dan terinspirasi dari budaya lokal bangsa Indonesia yang sangat beragam.

Merupakan kenyataan yang tak bisa ditolak bahwa negara-bangsa Indonesia terdiri dari berbagai kelompok etnis, budaya, agama dan lain-lain sehingga negarabangsa Indonesia disebut sebagai bangsa multikultural. Tetapi tataran praksis, realitas multikultural tersebut berhadapan dengan kebutuhan mendesak untuk merekonstruksi kembali "kebudayaan nasional Indonesia" yang dapat menjadi "integrating force" yang mengikat seluruh keragaman etnis, agama dan budaya tersebut. Ben Senang Galus dalam Menalar Negara (2014). Pemahaman nilai-nilai multikultural pada peserta didik akan menjadi fundasi yang kuat untuk diterapkan di dalam kehidupan sekolah maupun dalam masyarakat. Melalui nilai-nilai yang terkandung di dalamnya, diharapkan dapat membangkitkan semangat persudaraan dan tenggang rasa, gotong royong dan toleransi yang mengikat perbedaan.

Kurikulum mata pelajaran sejarah mengandung nilai-nilai berharga dalam kehidupan. Materi pelajaran sejarah mempunyai potensi dalam menanamkan nilai -nilai yang mengandung penghargaan terhadap masyarakat multikultural di Indonesia agar bisa menjadi manusia yang berkarakter unggul. Warsono dkk. (2010) mengutip Jack Corley dan Thomas Philip (2000) menyatakan: "Karakter merupakan sikap dan 
kebiasaan seseorang yang memungkinkan dan dan mempermudah tindakan moral.". Tindakan moral anak bangsa harus mencerminkan krakter bangsa Indonesia yang sangat menjunjung tinggi gotong royong dan solider yang berbudi luhur harus bisa diejawantahkan dalam pendidikan kita dengan menjunjung tinggi Pancasila sebagai sumber dari perilaku dan pandangan hidup bernegara.

\section{DAFTAR PUSTAKA}

Aman. 2011. Model Evaluasi Pembelajaran Sejarah. Yogyakarta: Ombak.

Abdurrahman, Dudung. 2007. Metodologi Penelitian Sejarah. Yogyakarta: Ar-Ruz Media

Galus, S. Ben 2014. Menalar Negara: Perspektif Politik, Biro-krasi, Pendidikan Lingkungan Hidup, Dan Kebudayaan. Yogyakarta: Beta

Ghufron, A dkk. 2017. Pengembangan Pembelajaran Berbasis Nilai-Nilai Budaya Yogyakarta Di Sekolah Dasar. Jurnal Cakrawala Pendidikan Vol. 36 (2) Hal. 318309. Yogyakarta: Universitas Negeri Yogyakarta

Hasan. S. H. 2007. Kurikulum Pendidikan Sejarah Berbasis Kompetensi. Makalah Pada Seminar Nasional Ikatan Himpunan Mahasiswa Sejarah Se-Indonesia (Ikahimsi) XII. Semarang, 16 April 2017.

Kochhar, S.K. 2008. Pembelajaran Sejarah. Jakarta: Grasindo.

Patminingsing, N. 1994. Penuntun Belajar Sejarah. (Nasional dan Umum) Surakarta Bandung :Ganeca Exact.

Sanjaya, Wina. 2006. Strategi Pembelajaran Berorientasi Standar Proses Pendidikan. Jakarta: Kencana Prenada Media

Tilaar, H.A.R. 2004. Multikulturalisme tantangan-tantangan global masa depan dalam transformsi pendidikan nasional, Jakarta: Grasindo

Undang-Undang Nomor 20 Tahun 2003 tentang Sistem Pendidikan Nasional.

Warsono, dkk, 2010. Model pendidikan Karakter di Universitas Negeri Surabaya: Unesa. 